\title{
4H Silicon Carbide Etching Using Chlorine Trifluoride Gas
}

\author{
Hitoshi Habuka ${ }^{1, a}$, Yusuke Katsumi ${ }^{1, a}$, Yutaka Miura, a, Keiko Tanaka, a , \\ Yasushi Fukai 2, b, Takaya Fukae ${ }^{2, c}$, Yuan Gao ${ }^{2, \text { b }}$, Tomohisa Kato ${ }^{3, d}$, \\ Hajime Okumura $^{3, \mathrm{e}}$ and Kazuo Arai ${ }^{3, \mathrm{f}}$
}

\author{
${ }^{1}$ Yokohama National University, 79-5 Tokiwadai Hodogaya Yokohama 240-8501, Japan \\ ${ }^{2}$ New Products Development Division, Kanto Denka Kogyo Co., Ltd., 1-2-1 Marunouchi, Chiyoda, \\ Tokyo 100-0005, Japan. \\ ${ }^{3}$ Power Electronics Research Center, National Institute of Advanced Science and Technology, \\ AIST Tsukuba Central2, 1-1-1 Umezono, Tsukuba, Ibaraki 305-8568, Japan. \\ ahabuka1@ynu.ac.jpl, bko@kantodenka.co.jp, ${ }^{\mathrm{c}}$ fukae@kantodenka.co.jp ${ }^{\mathrm{d}}$ t-kato@aist.go.jp, \\ eh-okumura@aist.go.jp, 'arai-kazuo@aist.go.jp
}

Keywords: $4 \mathrm{H}-\mathrm{SiC}$, chlorine trifluoride, dry etching, surface morphology

\begin{abstract}
The etching technology for $4 \mathrm{H}$-silicon carbide $(\mathrm{SiC})$ was studied using $\mathrm{ClF}_{3}$ gas at $673-973 \mathrm{~K}, 100 \%$ and atmospheric pressure in a horizontal reactor. The etch rate, greater than 10 $\mathrm{um} / \mathrm{min}$, can be obtained for both the C-face and Si-face at substrate temperatures higher than 723 $\mathrm{K}$. The etch rate increases with the increasing $\mathrm{ClF}_{3}$ gas flow rate. The etch rate of the Si-face is smaller than that of the C-face. The etched surface of the Si-face shows many hexagonal-shaped etch pits. The $\mathrm{C}$-face after the etching is very smooth with a very small number of round shaped shallow pits. The average roughness of the etched surface tends to be small at the higher temperatures.
\end{abstract}

\section{Introduction}

Silicon carbide ( $\mathrm{SiC})$ has various useful properties. However, due to its chemically and mechanically stable nature, the $\mathrm{SiC}$ wafer preparation is very difficult, particularly, for obtaining a smooth surface and for removing the damaged layer caused by various mechanical processes. Therefore, in this study, the $\mathrm{SiC}$ etching technology using $\mathrm{ClF}_{3}$ gas were studied, particularly about the etch rate, the surface roughness and the etched surface morphology of the single-crystalline $4 \mathrm{H}-\mathrm{SiC}$ substrate.

\section{Experimental}

The substrate used in this study is the polished n-type single-crystalline $4 \mathrm{H}-\mathrm{SiC}$ wafer having a (0001) surface, 8 -degrees off-oriented to $<11-20>$. This substrate has nitrogen as the n-type dopant at the concentration of $3-5 \times 10^{18} \mathrm{~cm}^{-3}$.

In order to etch the Si-face (0001) and C-face (000-1) of the $4 \mathrm{H}-\mathrm{SiC}$ using the chlorine trifluoride gas, the horizontal cold-wall reactor shown in Fig. 1 was used. This reactor consists of a gas supply system, a quartz chamber and infrared lamps. Hydrogen gas was used in order to remove the silicon oxide film and the organic contamination on the substrate surface. This reactor has a small cross section above the substrate in order to achieve a very high consumption efficiency of the chlorine trifluoride gas. The height and the width of the quartz chamber are $10 \mathrm{~mm}$ and $40 \mathrm{~mm}$, respectively, similar to our previous studies $[1,2]$.

A $30 \mathrm{~mm}$ wide $\times 50 \mathrm{~mm}$ long $\times 0.2 \mathrm{~mm}$ thick polycrystalline $3 \mathrm{C}$-SiC wafer produced by the chemical vapor deposition method (Admap Inc., Tokyo) was horizontally held on the bottom wall of the quartz chamber as the susceptor. The $4 \mathrm{H}-\mathrm{SiC}$ substrate, having $5 \mathrm{~mm}$ wide x $5 \mathrm{~mm}$ long x 0.4 $\mathrm{mm}$ thick dimensions, was placed on the center of the $3 \mathrm{C}-\mathrm{SiC}$ susceptor. The substrate and the susceptor were simultaneously heated by infrared rays emitted from halogen lamps through the quartz chamber walls. 
The entire process used in this study mainly consisted of the following three steps:

(a) cleaning the substrate surface by baking at $1373 \mathrm{~K}$ for $10 \mathrm{~min}$ in ambient hydrogen,

(b) changing the ambient gas from hydrogen to nitrogen, and

(c) etching the substrate surface using the chlorine trifluoride gas.

During step (a), hydrogen gas was introduced into the reactor at atmospheric pressure at the flow rate of $21 / \mathrm{min}$. The etch rate and the change in the surface roughness after step (a) were determined to be negligible. In step (b), the quartz chamber and the substrate were cooled to room temperature. The hydrogen gas present in the quartz chamber was sufficiently purged with nitrogen gas in order to avoid any explosive reaction between the hydrogen gas and chlorine trifluoride gas. During step (c), the substrate was heated and adjusted to a temperature between $673 \mathrm{~K}$ and $973 \mathrm{~K}$. The substrate was then etched by the chlorine trifluoride gas ( $>99.9 \%$, Kanto Denka Kogyo Co., Ltd., Tokyo) without further purification. The chlorine trifluoride gas flow rate was $100-300 \mathrm{sccm}$. The average etch rate of the $4 \mathrm{H}-\mathrm{SiC}$ by the chlorine trifluoride gas was determined by the decrease in the substrate weight.

The surface morphology of the $4 \mathrm{H}-\mathrm{SiC}$ substrate before and after the etching was observed using an optical microscope (VC4500-PC, OMRON Corp., Kyoto). The shape of the surface pits was observed using an atomic force microscope (AFM) (Hybrid Microscope Nanoscale VN-8000, Keyence Co., Ltd., Tokyo). The average roughness, $R_{\mathrm{a}}$, measurement was performed along a 0.2 $\mathrm{mm}$ length at the center of the substrate using the SURTRONIC Duo (Taylor Hobson, Limited, UK). The lowest measurement limit of $R_{\mathrm{a}}$ was $10 \mathrm{~nm}$ in this study.

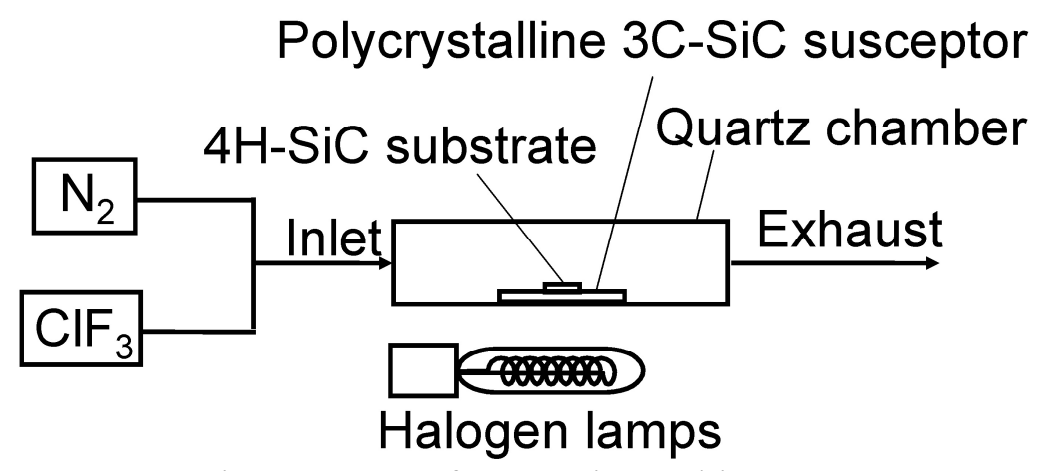

Fig. 1 Reactor for 4H-SiC Etching.

\section{Results and Discussion}

Fig. 2(a) shows the etch rate of the Si-face of the $4 \mathrm{H}-\mathrm{SiC}$ substrate using chlorine trifluoride gas at the concentration of $100 \%$ and at atmospheric pressure in the temperature range between 673 and $973 \mathrm{~K}$. The white square and dark square denote the etch rate at 100 and $200 \mathrm{sccm}$, respectively. The Si-face etch rate at a substrate temperature less than $723 \mathrm{~K}$ is less than $1 \mathrm{um} / \mathrm{min}$. At a substrate temperature near $723 \mathrm{~K}$, the etch rate significantly increases. The Si-face etch rate becomes greater than $7 \mathrm{um} / \mathrm{min}$ and maintains its value at substrate temperatures greater than $773 \mathrm{~K}$ in the reactor used in this study. Although the etch rate at the chlorine trifluoride gas flow rate of $200 \mathrm{sccm}$ was not measured at the lower temperatures, the trend in the flat etch rate at the higher temperatures and the small etch rate at the lower temperatures is considered to be the same as that at $100 \mathrm{sccm}$ and that for the polycrystalline $3 \mathrm{C}-\mathrm{SiC}[1,2]$.

Fig. 2 (b) shows the etch rate of the $\mathrm{C}$-face of the $4 \mathrm{H}-\mathrm{SiC}$ substrate using chlorine trifluoride gas $(100 \%)$ at atmospheric pressure in the temperature range between 723 and $973 \mathrm{~K}$. The white circle and dark circle denote the etch rate at the chlorine trifluoride gas flow rates of 100 and 200 sccm, respectively. The $\mathrm{C}$-face etch rate shows a significant increase near $723 \mathrm{~K}$, and it maintains its value at substrate temperatures greater than $773 \mathrm{~K}$, similar to the Si-face etch rate. The C-face etch rates at higher temperatures are $9 \mathrm{um} / \mathrm{min}$ and $14 \mathrm{um} / \mathrm{min}$ at the chlorine trifluoride gas flow rates of $100 \mathrm{sccm}$ and $200 \mathrm{sccm}$, respectively. 
Figs. 3 (a) and 3 (b) show the etch rate of the Si-face and the C-face, respectively, of the $4 \mathrm{H}-\mathrm{SiC}$ substrate by chlorine trifluoride gas $(100 \%)$ at atmospheric pressure, when changing with the chlorine trifluoride gas flow rate. The circle, square and triangle denote the etch rate at the substrate temperatures of 773, 873 and $973 \mathrm{~K}$, respectively. As shown in these figures, the Si-face and $\mathrm{C}$-face etch rates increase with the gas flow rate of the chlorine trifluoride gas. Additionally, the etch rate at 773, 873 and $973 \mathrm{~K}$ overlap each other for both the Si-face and the C-face, consistent with Figs. 2 (a) and 2 (b). The etch rate of the Si-face is about $60 \%$ of that of the C-face. The relationship between the $\mathrm{Si}$-face etch rate and the $\mathrm{C}$-face etch rate is similar to that of another etching technique, such as the potassium hydroxide method. [3]

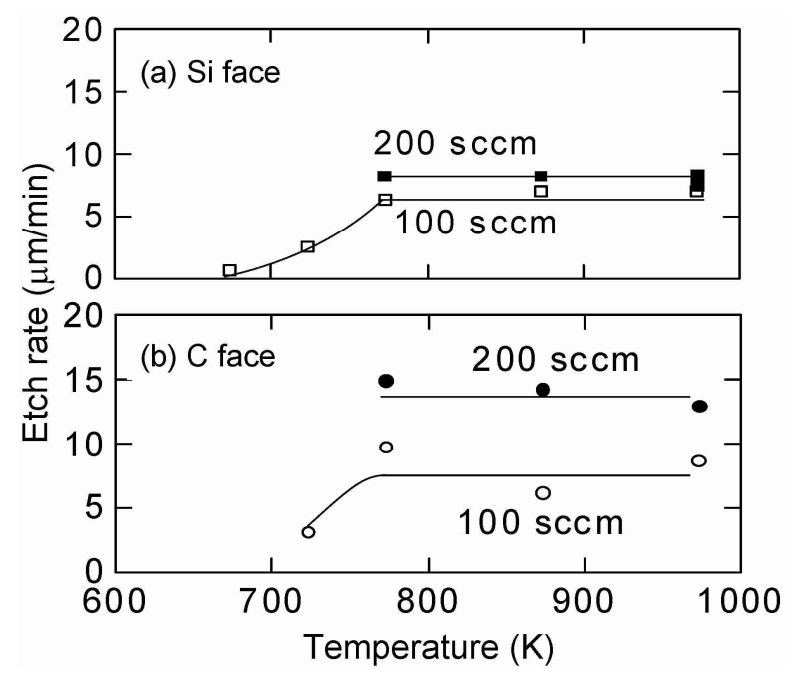

Fig. 2 4H-SiC Etch rate at $673-973 \mathrm{~K}$ $\left(\mathrm{ClF}_{3}: 100 \%\right)$.

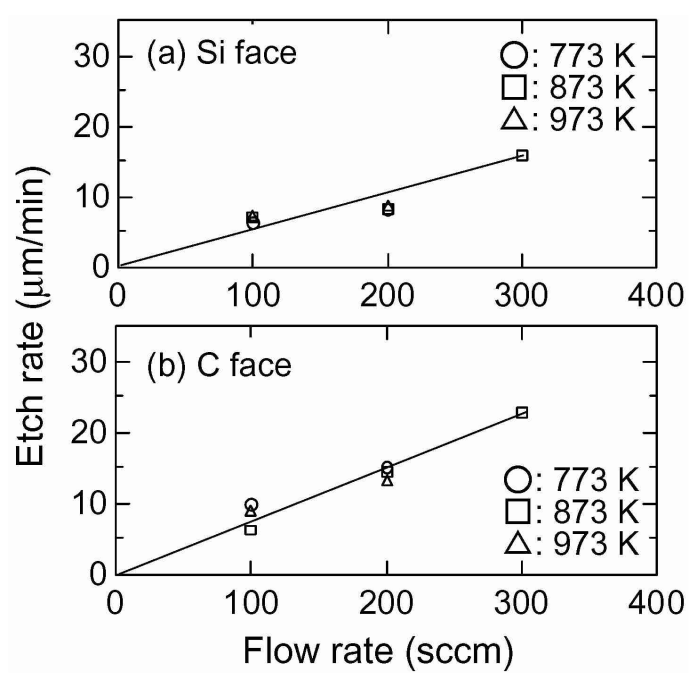

Fig. 3 4H-SiC Etch rate at 100-300 sccm $\left(\mathrm{ClF}_{3}: 100 \%\right)$.

Although many etch pits appeared at the surface of $\mathrm{Si}$-face $4 \mathrm{H}-\mathrm{SiC}$, due to this etching, C-face showed very smooth surface. The $R_{\mathrm{a}}$ roughness of Si-face decreased with increasing the $\mathrm{ClF}_{3}$ gas flow rate, as shown in Fig. 4.

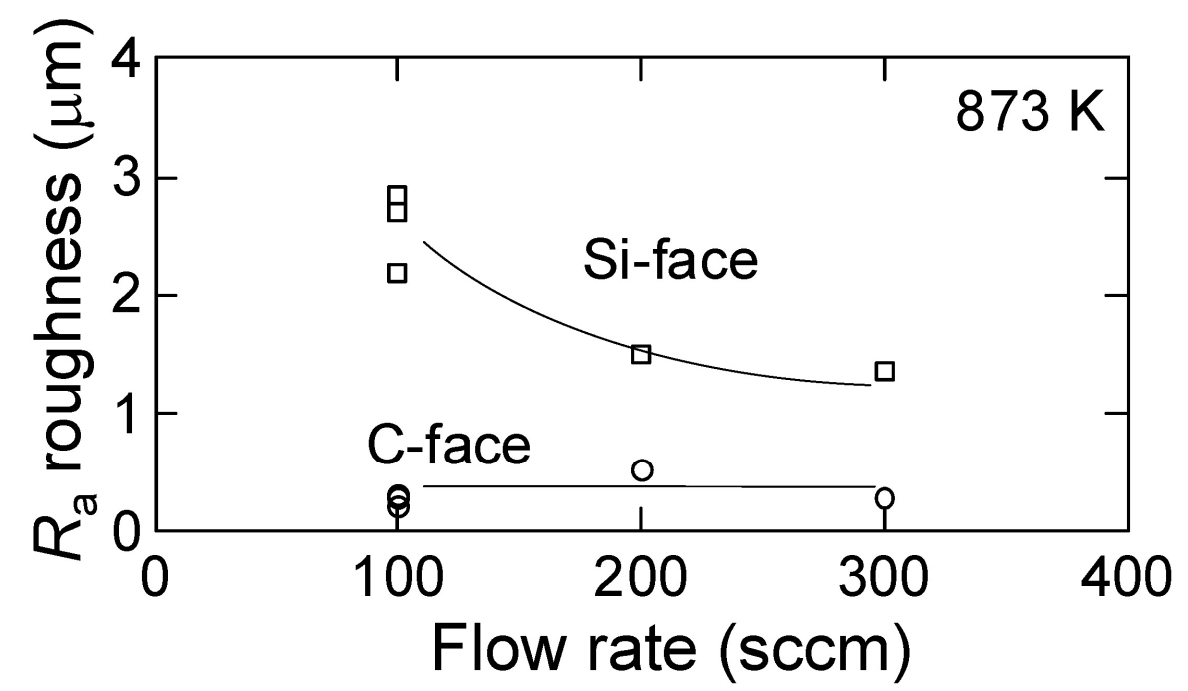

Fig. $4 R_{\mathrm{a}}$ roughness of $\mathrm{Si}$ - and $\mathrm{C}$-face $\left(\mathrm{ClF}_{3}: 100 \%, 873 \mathrm{~K}\right)$.

In order to clearly observe the pit shape formed by the chlorine trifluoride gas, AFM photographs were taken, as shown in Fig. 5. In this figure, direction $<11-20>$ was not identified. 
Figs. 5(a) and (b) show the pits on the Si-face and C-face, respectively, after the etching using the chlorine trifluoride gas (100\%) at atmospheric pressure for $3 \mathrm{~min}$ at $873 \mathrm{~K}$ and $300 \mathrm{sccm}$. Fig. 5(a) reveals a nearly hexagonal edge shape having a flat-shaped bottom. Its diameter and depth are about $0.03 \mathrm{~mm}$ and 2000-3000 $\mathrm{nm}$, respectively. The many pits that exist over the entire surface are shown to have the same edge and bottom shape as that shown in Fig. 5(a). Fig. 5(b) shows the pit shape on the C-face. This surface is very flat and smooth having only a very small number of circular shaped pits, which are very shallow with a diameter of $0.01 \mathrm{~mm}$ and a depth of about 200 $\mathrm{nm}$. The relationship between the etch pits and crystal defect should be studied in our future work.
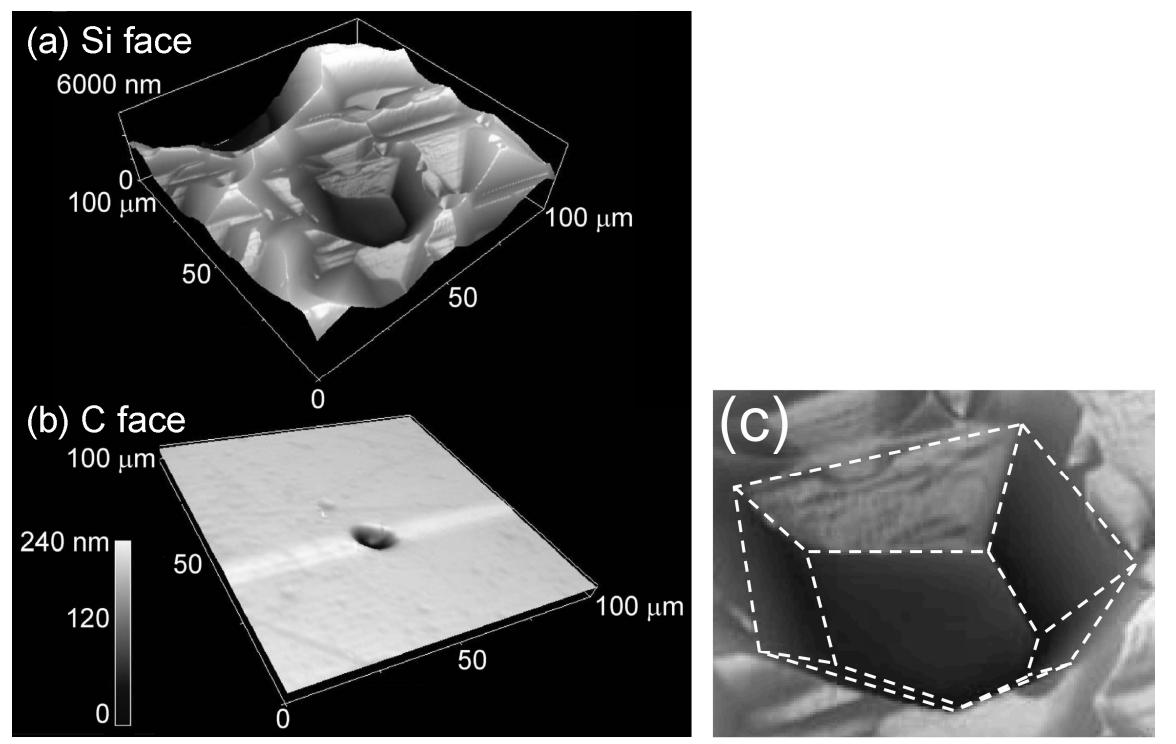

Fig.5 Etch pits on (a) Si-face and (b) C-face $\left(873 \mathrm{~K}, \mathrm{ClF}_{3}: 100 \%, 300 \mathrm{sccm}\right)$. (c) is the magnification of the pit in (a), the edge of which is traced using dotted line.

\section{Conclusions}

The etching method of $4 \mathrm{H}$-silicon carbide $(\mathrm{SiC})$ was studied using $100 \%$ chlorine trifluoride gas at $673-973 \mathrm{~K}$ and atmospheric pressure in a horizontal reactor. The etch rate, greater than 10 $\mathrm{um} / \mathrm{min}$, can be obtained for both the C-face and Si-face at substrate temperatures higher than 723 $\mathrm{K}$. The etch rate is proportional to the chlorine trifluoride gas flow rate. The etch rate of the Si-face is smaller than that of the C-face. The maximum etch rate obtained in this study is $23 \mathrm{um} / \mathrm{min}$ for the $\mathrm{C}$-face. The etched surface of the Si-face shows many hexagonal-shaped etch pits having a flat bottom. The $\mathrm{C}$-face after the etching is very smooth with a very small number of round shaped shallow pits. The average roughness of the etched surface tends to be low at the higher temperatures.

\section{Acknowledgments}

The authors thank Profs. H. Kunieda and K. Aramaki of Yokohama National University for taking the photographs of the $\mathrm{SiC}$ surface using a digital optical microscope. They also thank Drs. T. Takeuchi and M. Aihara for their fruitful discussion.

\section{References}

[1] H. Habuka, S. Oda, Y. Fukai, K. Fukae, T. Sekiguchi, T. Takeuchi, and M. Aihara, Jpn. J. Appl. Phys. vol. 44 (2005) p. 1376.

[2] H. Habuka, S. Oda, Y. Fukai, K. Fukae, T. Takeuchi and M. Aihara, Thin Solid Films, vol. 514 (2006) p. 193.

[3] H. Matsunami (Ed.), Technology of Semiconductor SiC and its application, P. 99, Nikkan Kogyo (Tokyo, 2003). [In Japanese] 